\title{
Triple interest of imaging in Lemierre syndrome: A case report
}

\author{
Ahoury N'guessan Judicael ${ }^{* 1}$, Salami Fatima Adéniké ${ }^{1}$, Gui-Bilé LN², N'zi Kouassi Paul ${ }^{1}$, Touré Aboulaye ${ }^{3}$ \\ ${ }^{1}$ Department of Radiology, Institute of Cardiology, Abidjan, Côte d'lvoire \\ ${ }^{2}$ Department of Radiology, University Hospital in Treichville, Abidjan, Côte d'Ivoire \\ ${ }^{3}$ Department of Radiology, University Hospital in Yopugon, Abidjan, Côte d'Ivoire
}

Received: May 16, 2016

DOI: $10.5430 / j b g c . v 6 n 2 p 4$
Accepted: June 2, 2016

Online Published: June 13, 2016

\begin{abstract}
Oropharyngeal infections can sometimes be complicated by Lemierre syndrome (LS), which is a septic thrombophlebitis of the internal jugular vein. This is a diagnostic and therapeutic emergency. It must be systematically suspected in a patient presenting oropharyngeal infection, clinical signs of sepsis and cervical swelling and pain. Cervical and thoracic computed tomography is absolutely necessary with a triple interest; diagnosis, prognosis and therapy.
\end{abstract}

Key Words: Lemierre syndrome, Thrombophlebitis, CT scan

\section{INTRODUCTION}

Lemierre syndrome (LS) is a septic thrombophlebitis of the internal jugular vein (IJV) or its tributaries. It is potentially fatal and usually due to Fusobacterium necrophorum which is ENT flora commensal. ${ }^{[1]}$ Diagnosis is based on imaging and blood cultures that isolate the germ.

We present a case of LS with important Neck necrotizing cellulitis. The imaging confirmed the diagnosis, specify the extension and lead the therapeutic choice.

\section{ObServation}

A 45 years old smoking patient consulted in stomatology for an extensive skin necrosis following a left cervical swelling. The symptoms began with left ear pain, odynophagia, fever and a left cervical swelling. Four days later, we noticed a left cervical skin necrosis and pus. Clinical examination revealed pale conjunctiva, fever $\left(38.9^{\circ} \mathrm{C}\right)$, dehydration, painful submandibular lymphadenopathy and an extensive left cervical skin necrosis exposing the sternocleidomastoid muscle (see Figure 1).

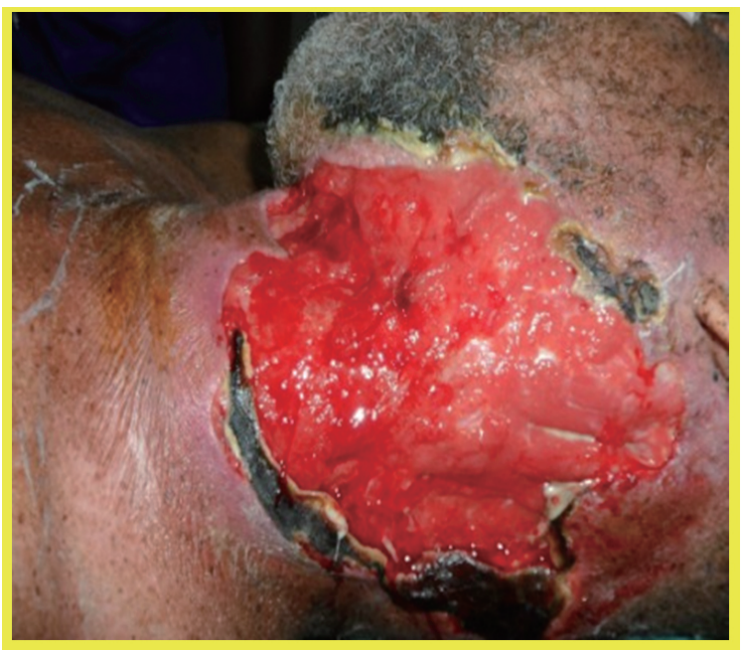

Figure 1. Clinical aspect of patient

\footnotetext{
${ }^{*}$ Correspondence: Ahoury N'guessan Judicael; Email: ahouryjudi@yahoo.fr; Address: Department of Radiology, Institute of Cardiology, Abidjan, Côte d'Ivoire, BP V206 Abidjan-Côte d'Ivoire. 
ENT examination showed an inflammation of the posterior pharyngeal wall with enlarged and irritated tonsils. Cardiopulmonary auscultation was normal. Blood examinations revealed microcytic anemia $(7 \mathrm{~g} / \mathrm{dl})$, hyperleukocytosis $\left(17.103\right.$ elts $\left./ \mathrm{mm}^{3}\right)$ and negative retroviral HIV serology. ECG and chest X-ray were normal. The cervical CT scan showed dilation of the left IJV with intra luminal hypodensity and healthy adjacent carotid (see Figure 2).

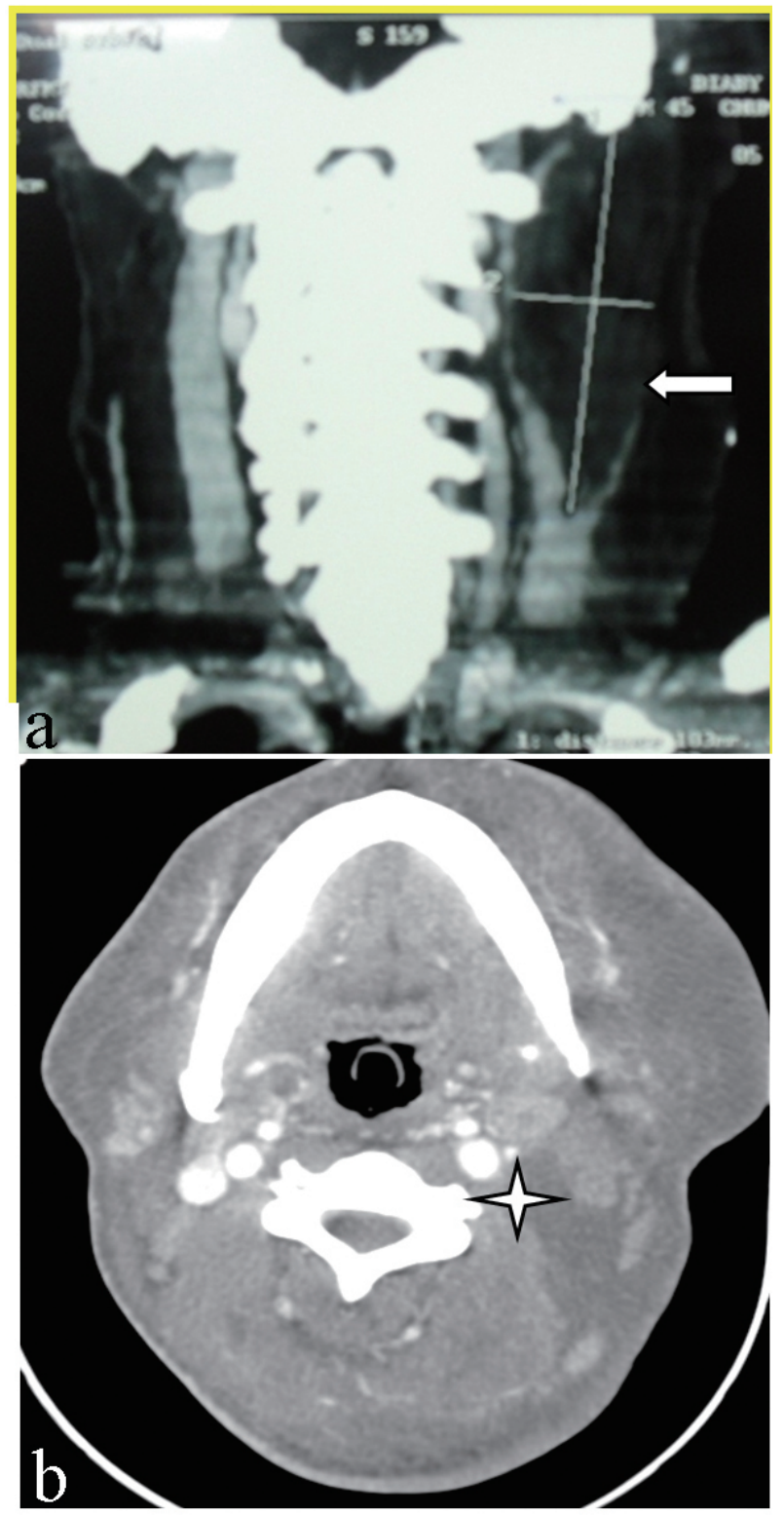

Figure 2. Intraluminal dilation and hypodensity of the left IJV (a, arrow), not Clouded (b, star) with cervical abscess collection

It's have been realized a surgical debridement of the cellulitis, administration of antibiotics and extraction of the thrombus after ligation-section of the IJV. A control CT scan realized Published by Sciedu Press four days postoperatively showed interruption of the left IJV and especially the development of its collateral branches (see Figure 3).

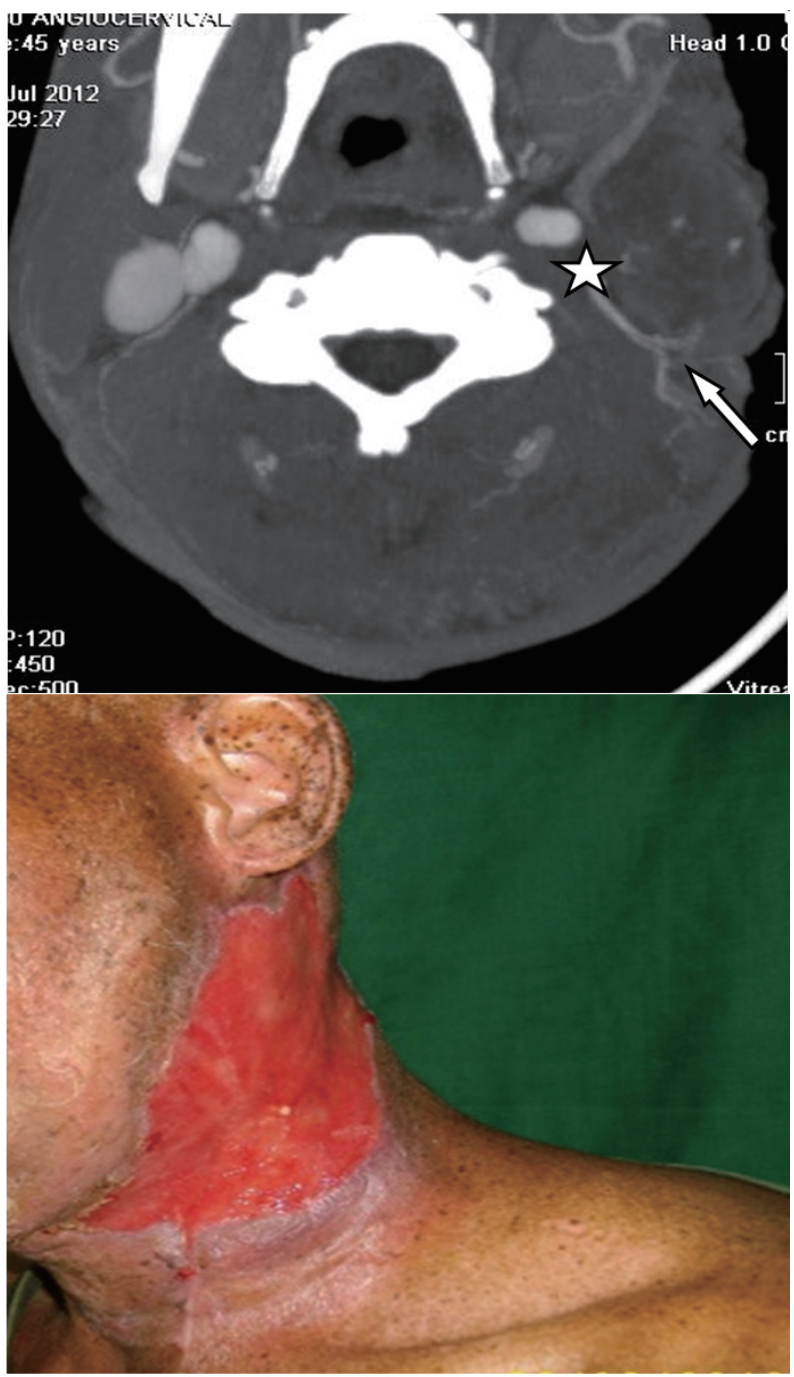

Figure 3. Interruption of the left IJV (star) and development of Locum veins (arrow). Aspect of patient after surgery

\section{Discussion}

Lemierre syndrome is a rare condition which typically complicates an ENT infection, usually angina. ${ }^{[2]}$ Other gateways are discussed such as poor dental status (alcohol and tobacco), sinusitis, mastoiditis and ear infections. Our patient was smoking.

The absence of the germ in blood cultures should not reject the diagnosis because Fusobacterium necrophorum grows slowly. ${ }^{[3]}$ Bacteriological examination of pus and blood cultures were not isolated the germ in our patient; this observation is superimposed on that of Perrin et al. ${ }^{[4]}$ in which no bacteriological documentation could be obtained for three patients, despite the numerous blood and surgical specimens. 
Clinically, the patient had a sore throat, enlarged lymph nodes and fever.

The symptoms may be accompanied by odynophagia, painful cervical swelling and neck pain. ${ }^{[5]}$ We can also see clinical manifestations related to pulmonary, abdominal and cardiovascular dissemination of infection.

Imaging has a key role to show ENT achievement, vascular and metastasis. The cervical CT scan with contrast injection shows the presence and accurate extension of thrombophlebitis of the IVJ and its tributaries, this is the diagnostic value. In our patient the CT scan confirmed the diagnosis and eliminated the infected tumor or diffuses necrotizing cellulitis.

Thrombosis was too extensive so it requires a vascular surgery. The CT scan aims the status of the carotid whose achievement (breaking) by contiguity is fatal due to the cataclysmic hemorrhage it can cause. Our patient had a healthy carotid. In the literature the carotid artery lesion may be a stenosis, occlusion or an aneurysm. ${ }^{[6]}$ This is the prognostic value of the CT scan which also made the diagnosis of septic metastasis (lung, pericardium, and joints) and is involved in the postoperative follow-up, showing the compensate venous system whose quality can plan the skin graft.

The Doppler ultrasound can visualize thrombophlebitis showing increased vein diameter, incompressible and an absence of flow but remains limited. It is operator dependent and does not explore the totality of the jugular vein (retroclavicular portion of the skull base), a fresh thrombus not yet organized can be disregarded. ${ }^{[6,7]}$ Chest radiography may show septic pulmonary emboli. ${ }^{[8]}$ In our patient cardiopulmonary auscultation and chest radiograph were normal. Some authors recommend a chest CT scan immediately; it is more sensitive than radiography and shows earlier septic pulmonary infarction. ${ }^{[4]}$

The therapeutic management based on appropriate antibiotic therapy, sometimes supplemented by ENT surgery.

\section{Conclusion}

Often unrecognized pathology, Lemierre syndrome is a medico-surgical emergency requiring rapid diagnosis to limit complications. Cervical CT scan is essential for the diagnosis with a triple diagnosis, prognostic and therapeutic interest.

\section{Conflicts OF InTEREST Disclosure}

The authors declare that they have no conflicts of interests.

\section{REFERENCES}

[1] Srivali N, Ungprasert P, Kittanamongkolchai W. Lemierre's syndrome: An often missed life-threatening infection. Indian J Crit Care Med. 2014; 18(3): 170-2. PMid:24701068. http://dx.doi.org $/ 10.4103 / 0972-5229.128708$

[2] Johannesen K, Bødtger U, Heltberg O. Lemierre's syndrome: the forgotten disease. J Thromb Thrombolysis. 2014; 37(3): 2468. PMid:23686643. http://dx.doi.org/10.1007/s11239-013 -0931-y

[3] Monge M, Aubry P, Dayen C. Le syndrome de Lemierre: exceptionnel, mais encore possible. Ann Med Interne. 2003; 154: 263-6.

[4] Perrin MA, Jankowski A, Righini C. Syndrome de Lemierre: apport de l'imagerie. J Radiol. 2007; 88: 65-8. http://dx.doi .org/10. 1016/S0221-0363(07) 89791-5
[5] Shook J, Trigger C. Lemierre's Syndrome. West J Emerg Med. 2014; 15(2): 125-6. PMid:24672595. http://dx.doi.org/10.5811/w estjem.2013.12.20418

[6] Nguyen-dihn KV, Marsot-Dupuch K, Portier F. Lemierre syndrome: usefulness of CT in detection of extensive occult thrombophlebitis. J Neuroradiol. 2002; 29: 132-5. PMid:12297736.

[7] Golpe R, Marín B. Lemierre's syndrome (necrobacillosis). Postgrad Med J. 1999; 75: 141-4. http://dx.doi .org/10.1136/pgmj . 75 .881 .141

[8] Screaton NJ, Ravenel JG, Lehner JG. Lemierre syndrome: forgotten but not extinct, report of four cases. Radiology. 1999; 213: 36974. PMid:10551214. http://dx.doi.org/10.1148/radiology .213.2.r99nv09369 